\title{
Eskişehir'in Turistik Destinasyon Çekim Unsurlarının Yerel Basındaki Sunumu
}

\author{
Çağdaş Aydın (Arş. Gör.) \\ Anadolu Üniversitesi Sosyal Bilimler Enstitüsü \\ cagdasaydin@anadolu.edu.tr \\ ORCID: 0000-0003-3194-4218 \\ Ceren Aydın \\ Anadolu Üniversitesi Sosyal Bilimler Enstitüsü \\ cerendiktas@anadolu.edu.tr \\ ORCID: 0000-0001-8325-5743
}

Başvuru Tarihi: 01.08.2019

Yayına Kabul Tarihi: 04.11.2019

Yayınlanma Tarihi: 24.01.2020

DOI: http://10.17680/erciyesiletisim.599682

\section{Öz}

$\mathrm{Bu}$ çalışmanın amacı, Eskişehir'in turistik çekim unsurlarının yerel basında okuyucuya nasıl aktarıldığının belirlenmesidir. Bu kapsamda yerel gazetelerde çıkan turizm içerikli haberler ve köșe yazıları, yerel gazetelerin web sayfaları üzerinden araştırmacılar tarafından incelenmiștir. Gazetelerde turizm ile ilgili ele alınan yazıların türü, kökeni ve haber kaynakları detaylı bir biçimde irdelenmiştir. Benzer bir biçimde turizmle ilgili yazıların teması ve alt konuları belirlenmiş , bu yazıların bireyleri destinasyona çekecek unsurları içerip içermediği araştırılmıştır. Çalışmada nitel araştırma yaklaşımlarından biri olan doküman taramasından yararlanılmıștır. $\mathrm{Bu}$ kapsamda Eskişehir ilinde çıkarılan yerel gazeteler araştırmacılar tarafından belirlenmiş ve toplamda sekiz yerel gazeteye ulaşılmıştır. Bu gazeteler; İstikbal, Eskişehir Anadolu, Sakarya, 2 Eylül, Milli İrade, Sonhaber, Şehir ve Yenigün șeklinde sıralanmaktadır. Bu gazetelerden Şehir ve İstikbal gazetelerinin web sayfalarının arama özelliği olmamasından dolayı araștırma kapsamından çıkarılmış ve araştırmaya diğer altı gazete üzerinden devam edilmiştir. Bu altı gazete üzerinden "haberlerin yayın sayıları, "yayın türü", "kökeni", "bilgi kaynağı", "haber içeriklerinin niteliği", "görsel malzemelerin sunumu" ve "Eskişehir'in çekicilikleri" olmak üzere yedi değişken kapsamında turizm yazıları içerik analizine tabii tutulmuştur. Toplamda 535 turizm yazısı incelenmiştir. Yapılan içerik analizi sonucunda kamu kurumlarının, Eskișehir turizmi için en önemli bilgi kaynakları olduğu görülmüștür. Bu noktada özel sektörün Eskişehir turizmiyle ilgili yapılan haberlere bilgi kaynağı olabilme rolünün oldukça kısıtlı olduğu söylenebilir. Diğer yandan yazılan haberlerin içeriğinin, "ümit veren" ve "bilgi veren" özellikte olduğu belirlenmiştir

Anahtar Kelimeler: Destinasyon Çekiciliği, Turizm Haberleri, Yerel Gazeteler, Eskişehir. 


\title{
Presentation of Eskișehir's Destination Attractions in Local Media
}

\author{
Çağdaş Aydın (Res. Asst.) \\ Anadolu University Institute of Social Sciences \\ cagdasaydin@anadolu.edu.tr \\ ORCID: 0000-0003-3194-4218 \\ Ceren Aydın \\ Anadolu University Institute of Social Sciences \\ cerendiktas@anadolu.edu.tr \\ ORCID: 0000-0001-8325-5743
}

Date Received: 01.08.2019

Date Accepted: 04.11.2019

Date Published: 24.01.2020

DOI: http://10.17680/erciyesiletisim.599682

\begin{abstract}
The aim of this study is to determine how tourist attractions of Eskișehir are presented to the reader in local press. Within this framework, news stories and articles involving tourism were studied by researchers as they appeared on the webpages of local media outlets. In the papers, the types, roots, and sources of information of tourism related articles were thoroughly inspected by researches. Similarly, the themes and subtopics of these articles were determined and questioned whether they involved elements which will attract individuals to the destination. In this study, document scanning method which is one of the qualitative research methods was employed. In this framework, the local newspapers of Eskișehir were determined by the researchers and eight local news outlets were specified. These papers are İstikbal, Eskişehir Anadolu, Sakarya, 2 Eylül, Milli İrade, Sonhaber, Şehir and Yenigün. Among these, Şehir and İstikbal were left out of the scope of the research due to the lack of a search function in their websites and the remaining six newspapers were investigated. On the basis of these six newspapers, tourism related articles' contents were analyzed via seven variables which are "publication numbers," "publication type," "source," "source of information," "the quality of news content," "presentation of images," and "attractions of Eskișehir." A total of 535 tourism articles were investigated. As the result of the content analysis, it was found that public institutions were the primary sources of information on Eskişehir's tourism. It can therefore be said that the possibility of being a source of information for the private sector for tourism related news stories were mostly limited. On the other hand, it was determined that the contents of the news articles were of "encouraging" and "informing" nature.
\end{abstract}

Keywords: Destination Attractions, Tourism News, Local Press, Eskişehir. 


\section{Giriş}

Kitle iletişim araçları 20. Yüzyıl'ın başlarında, toplum yaşamına girmiş ve zaman içinde toplumun davranışlarını etkileyen bir unsur olmuştur. Kitle iletişim araçlarıyla birlikte her türden düşünce, somut veya soyut ürünler tarihte hiç olmadığı kadar geniş bir kitleye ulaşabilme olanağı bulmuştur. Bu anlamda kitle iletişimi, toplumun ve toplumu oluşturan bireylerin gelişmesinde vazgeçilmez bir araç olarak görülmektedir (Timisi, 2003, 4142). Kitle iletişim araçlarında yer alan yayınlar kitlelerin davranışlarında, tercihlerinde ve algılamalarında değișikliğe neden olmaktadır (Singer ve Singer, 1998; Cılızoğlu, 2011, 90). Kitle iletişim araçlarından biri olan gazeteler sayesinde toplumun "ne hakkında" düşüneceği belirlenebilmektedir. Bu varsayımı destekler nitelikte gündem teorisini kapsamında kitle iletişim araçlarını ele alan çalışmalar bulunmaktadır. Bu çalışmalar, kitle iletişim araçlarının toplumda yer alan bireyin tutum ve hislerini etkilediğini göstermektedir (Milburn, 1998, 257). Kitle iletişim araçları özellikle turizm sektörü gibi rekabetin yoğun olduğu bir sektör içinde vazgeçilmezdir. Bunun nedeni ise turizm sektöründeki rekabetin birden fazla boyutunun olmasıdır. Turizm sektörü içinde yer alan ticari işletmelerin kendi aralarındaki rekabet hem de farklı destinasyonların birbirleri arasında yaşadıkları rekabet bu duruma örnek olarak verilebilir. Bu rekabet ülke içinde yer alan destinasyonlar arasında görülebilirken, bir üst boyutta ülkeler arası destinasyon rekabetinde de görülebilmektedir. Destinasyonlar bu rekabetten üstün çıkmak için, kitle iletişim araçları aracılığı ile destinasyon çekiciliklerini ön plana çıkaran bilgilerle gündemde yer almak istemektedir.

Turizme son yıllarda medyada geniş yer verilmektedir. Turizm medyada işlenirken gerek medyanın ekonomi içeriklerinde gerekse diğer bülten içeriklerinde kendisine oldukça fazla yer bulmaktadır. Bu durumun temel nedeni; turizm sektörünün birbirinden farklı birçok sektörle iç içe olmasıdır (Crouch, Jackson ve Thompson, 2005, 1-12). Destinasyonların doğal, tarihi, yapay ve kültürel çekiciliklerinin turizm anlamında pazarlanabilmesi için çeşitli faaliyetlere gereksinim duyulmaktadır. $\mathrm{Bu}$ faaliyetlerin en başında; destinasyona ilişkin reklamlarla, haberlerle ya da bölgede gerçekleştirilen sosyal sorumluluk projeleriyle medyada yer almaya çalışmak gelmektedir. Günümüzde insanlar belirli bir destinasyona gitmeden önce çeşitli bilgi kaynaklarına başvurmakta, gerek farklı ziyaretçilerin görüşlerine gerekse de söz konusu destinasyonun yerel bilgi kaynaklarına ulaşarak en doğru bilgiyi almaya çalışmaktadır (Bargeman ve Poel, 2006, 709). Bu kapsamda Eskişehir'in destinasyon çekicilik unsurları da gazetelerde kendine yer bulmaktadır. Bu çalışma kapsamında da yerel gazetelerde yer alan bu çekiciliklerin nitelik ve nicelik açısından incelenmesi amaçlanmıştır. Bu çerçevede, Eskişehir destinasyonuna ait çekiciliklerin, Eskișehir'de yayımlanan yerel ve bölgesel nitelikteki gazetelerde nasıl ele alındığı, içerik analizi uygulamasına dayalı olarak incelenmiştir. Eskișehir'in çekiciliklerinin yerel gazetelerde nasıl sunulduğunun belirlenmesi, çalışmanın alanyazına katkısını oluşturmaktadır. Diğer yandan, Eskişehir ilinin sahip olduğu çekiciliklerin ne ölçüde yerel gazetelerde yer aldığı ve bu çekiciliklerin hangi unsurlarla okuyuculara sunulduğu araştırılmıştır. Bu kapsamda yerel gazetelerin yeterince çekicilik unsurlarını ele alıp almadığı incelenmiştir. Gazetelerde yer alan haberlerin içerik açısından nasıl hazırlandığının belirlenmesi, gazeteler arasında karşılaștırmaların yapılması ve turizm haberleri kapsamında nelerin eksik bırakıldığının ortaya çıkarılması ise araştırmanın uygulamaya dönük katkısını ifade etmektedir. 


\section{Kavramsal Çerçeve}

Destinasyon kavramı Türk Dil Kurumu (TDK) sözlügünde "varılacak yer" olarak tanımlanmıştır (tdk.gov.tr, 2019). Ancak araştırmacıların tanımlamalarına bakıldığında birçok farklı tanım ve destinasyona atfedilmiş oldukça farklı özellik görülmektedir. Destinasyon tanımını yalnızca coğrafi bir bakışla ele alan Metelka $(1990,46)$, Medlik $(1993,148)$ ve Gunn $(1994,107)$; ülke, șehir veya kasaba gibi belirli sınırları olan coğrafi bölgeleri destinasyon olarak tanımlamıștır. Buhalis (2000, 97-98) ise destinasyon kavramını, turizm için gerekli olan temel kaynakları içinde barındıran, turizm faaliyetlerinin gerçekleștiği ve sunulan turistik mal ve hizmetler neticesinde turistik deneyimin oluştuğu ana zemin olarak yorumlamıștır. Destinasyon kavramına Buhalis'in yorumuna benzer bir şekilde yaklaşan Pride, Morgan ve Pritchard (2004, 1-15) ise turistlerin gereksinimlerini karşılamak için tasarlanan hizmet ve olanakların odak noktasını oluşturan coğrafi alan olarak destinasyonu nitelemişlerdir.

Destinasyon kavramına bu tanımların dışında coğrafi olarak kesin sınırlar çizmeyen tanımlarda bulunmaktadır. Bu tanımlar destinasyonu daha çok idari, sosyal ve kültürel bir alan olarak ifade etmektedir. Benzer bakışa sahip olan araștırmacılar turizm pazarlarındaki eğilimlerin değișebileceğini, bu değişimle birlikte çizilen destinasyon sınırlarının küçülebileceğini, büyüyebileceğini veya destinasyonların biçim değiştirebileceğini belirtmektedirler (Tosun ve Jenkins, 1996, 520; Usta, 2008, 225).

Turizm sektöründe destinasyonlar birçok farklı sınıflara ayrılmıştır. Bu sınıflandırmalar genel olarak üç grupta ele alınabilir. İlki sundukları hizmet alanlarına göre dinlenme, kültür, eğlence hizmeti sunan destinasyonlar olarak örneklendirilmektedir (Goeldner ve Ritchie, 2009, 277-279; Kozak, 2010, 143-144). İkincisi çekiciliklerine göre destinasyonlar olarak kent, yaz, dağ (kış), kırsal, otantik turizm destinasyonlarıdır (Buhalis, 2000, 101103). Sonuncu ve üçüncü sınıflandırmada ise coğrafi özelliklerine göre destinasyonlar; kıta, ülke, şehir, ilçe ve hatta koy gibi sinıflandırmalara tabii olurlar (Holloway, Humphreys ve Davidson, 2009, 15). Araştırma kapsamında alanyazın incelendiğinde, en çok kullanılan sınıflandırmanın ise Buhalis'in yaptığı sınıflandırma olduğu görülmüştür. Buhalis'in destinasyon sınıflandırması içinde yer alan kentsel destinasyon, araștırmanın temelini oluşturmaktadır.

Kentsel destinasyonlar turistik yer değiștirme hareketinin başladığu ilk günden bugüne kadar var olmuş bir destinasyon sınıflamasıdır. Kentler iş, spor, din ve dinlenme-eğlence turizmine yönelik birçok farklı turizm türünü barındırdığından turistler için her zaman bir çekim merkezi olmuştur (Türkeri, 2014, 37). Kentlerin tarihsel süreç içindeki yerine bakıldığında, Antik Yunan'ın Olimpiyat oyunlarıyla, hac kentlerinin dini ritüellerle, büyük metropollerin konferans ve sergilerle gündeme geldiği ve bu amaçlarla kentlerin bireyler tarafından sıklıkla ziyaret edildiği söylenebilir. Kentsel destinasyonlar; ulaşım konaklama, sosyal, kültürel, mimari çekiciliklerinin yanında sağlı hizmetleriyle de çekiciliklerini oluşturur (Karabıyık ve Sümer İnci, 2012, 4). Bu kapsamda düşünüldüğünde çekicilik unsurlarını etkin bir biçimde kullanan ve bu çekicilikleri bireylerin tercih kararlarında etkili olabilecek şekilde pazarlayan destinasyonların, turizm pastasındaki payı da yüksek olacaktır (Kim, Noh ve Jogaratnam, 2006).

Destinasyonlar, çekiciliklerini pazarlarken bölgeye gelen turistler gerek bu pazarlama unsurlarından gerekse de yakın çevrelerinden elde ettikleri duyumlar ve tecrübelerle destinasyon seçimine karar vermektedirler. Bu faktörler alanyazında itici faktörler (içsel) ve çekici (dışsal) faktörler olarak yer almaktadır (Yoon ve Uysal 2005, 47; Mohammad 
ve Mat Som, 2010, 42). Hsu, Tsai ve Wu (2009, 288-290) itici faktörleri "seyahate çıkma isteği" olarak tanımlarken;çekici faktörleri ise "gerçekçi destinasyon tercihi" olarak tanımlamıştır. Bu tanımlamalardan yola çıkarak, bireylerin içsel motivasyonları bireylerde seyahate çıkma isteğini artırmakta, ardından çekici faktörlerin yaratmış olduğu ek motivasyonla birlikte birey nereye seyahat edeceğini gerçekçi bir destinasyon seçimine dönüştürmektedir (Prayag ve Ryan, 2011, 122-125). Bireyleri seyahate iten faktörlere; dinlenmek, rahatlamak, bulunulan ortamdan kaçmak, aileyle birlikte olmak, sosyal etkileşimde bulunmak, yeni kültürler ve yeni yerler keşfetmek gibi güdüler örnek olarak verilebilir (Oh, Uysal ve Weaver, 1995, 127, 133-134). Bireyleri destinasyona çeken faktörler ise destinasyonda yer alan kıyı bölgeleri, sanatsal, kültürel ve sportif aktiviteler gibi destinasyona ait olan unsurlardır (Klenosky, 2002, 385).

Alanyazında turizm ve medya ilişkisini alan çalışmalara bakıldığında turizmin farklı bir çok türü üzerine çalışmalar yapıldığı görülmektedir. Sağlık turizmi içeriklerininin gazetelerdeki sunumunu inceleyen Ayrancı, Özmen, Yaşar ve Yüksel (2018); 2010-2015 yılları arasındaki gazeteleri incelemişlerdir. Toplamda 369 yazıyı inceleyen araștırmacılar, yıllar içinde sağlık turizminin gazetelerde daha fazla yer aldığını tespit etmişlerdir. Ayrıca araştırmacılar, çalışmada sağlık turizmi ile ilgili içeriklere daha çok iş adamları ve özel sektör temsilcilerinin kaynaklık ettiğini belirtmişlerdir. İlaveten araştırmacılar, çalışmada ele alınan içeriklerinin üreticisi olarak kurumun kendisinin veya muhabirin olduğu sonucuna ulaşmışlardır. Bu içeriklerin haber kaynakları olarak ise yerel yönetimlerin, sivil toplum kuruluşlarının olduğunu belirtmişlerdir. Araştırmacıların üzerinde durduğu bir başka unsur ise sağlık turizmi haberlerinin özellikle bahar aylarında daha sık gazetelerde kendine yer bulduğudur. Alanyazında yer alan bir diğer çalışma; geleneksel medyada giderek artan reklam harcamasına rağmen şirketlerin pazar paylarının düştügünü söyleyen ve eski reklam harcama modelleri yerine alternatiflerin aranması gerektiğini vurgulayan çalışmadır (Williams, 2006, 486). Ancak bu durum geleneksel medyayla turizm arasındaki ilișkinin azaldığına değil, yön değiștirmesi gerektiğine dair bir işarettir. Bu konuda araştırma yapan Lindström (2010), turizm ve medya arasındaki ilişkiyi değerlendirmenin ve bu ilişkiyi anlamanın, bir bölgeye yönelik destinasyon imajının oluşturulmasında, önemli bir aşama olduğunu belirtmiştir. Turizm ve medya arasındaki ilişkiyi Çorum turizmi özelinde inceleyen Ormankıran, Başçı ve Aknar (2016), Çorum turizmi ile ilgili haberlerin yaklaşı \% 90'ının olay-durum yazısı olduğunu, yalnızca \%10’unun köşe yazısından oluştuğunu saptamışlardır. Ayrıca araştırmacılar, haberler içinde görsel kullanılıp kullanılmadığınıda incelemiş, haberlerin \%52,90’ınında görsel kullanılmadığını belirtmiş̧lerdir. Çorum’la ilgili yapılacak tanıtımların Hattuşaş ve Hitit Medeniyeti ile ilişkilendirilmesi gerektiği, araştırmacılar tarafından vurgulanmıştır.

Kentsel bir destinasyon olarak Eskişehir ili ele alındığında şehrin sahip olduğu çekicilikler çeşitli pazarlama yöntemleriyle kamuoyuna duyurulmaktadır. Bu kapsamda da Eskişehir ilinin yerel gazetelerinde, Eskişehir destinasyonunun sahip olduğu çekiciliklerin yerel gazetelerdeki sunumu irdelenmiştir. Ayrıca destinasyon kavramı ile ilgili olarak alanyazın tarandığında, destinasyonlar kapsamında yapılan çalışmaların daha çok pazarlama, yönetim ve halkla ilişkiler kapsamında yapıldığı görülmektedir. Diğer yandan, destinasyonların basılı veya dijital ortamlarda nasıl sunulduğuna dair yapılan çalışmalar alanyazında kısıtlı kalmaktadır.

\section{Yöntem}

Araştırma kapsamında Eskişehir'in turistik destinasyon çekim unsurlarının yerel basında nasıl sunulduğu ortaya çıkarılmaya çalışılmıştır. Başka bir ifadeyle çalışmanın 
temel araştırma sorusu "Eskişehir'in turistik çekicilik unsurları yerel basında nasıl sunulmaktadır?" şeklindedir. Çalışmanın diğer araştırma soruları ise aşağıdaki gibidir;

1. Eskişehir yerel basınında, șehrin turizmi ile ilgili kaleme alınan yazıların türü, kökeni, bilgi ve haber kaynakları nelerdir?

2. Görsellerin kullanım oranı nedir? Görsellerin içerikleri nelerden oluşmaktadır?

3. Eskişehir turizmi ile ilgili ele alınan yazıların teması ve alt konuları nelerdir?

4. Diğer haberler içinde turizm haberlerinin Eskişehir yerel gazetelerindeki yeri nedir?

Çalışma kapsamında ele alınan sorulara yanıt aramak amacıyla çalışmada betimsel bir yaklaşım benimsenmiştir. Bu çerçevede çalışmada nitel araştırma yaklaşımlarından biri olan doküman taramasından yararlanılmıştır. İlk aşamada araştırmacılar, Eskişehir ilinin yerel gazetelerini belirlemişlerdir. Söz konusu gazeteler; İstikbal, Eskişehir Anadolu, Sakarya, 2 Eylül, Milli İrade, Sonhaber, Şehir ve Yenigün gazeteleridir. Bu gazetelerden Şehir ve İstikbal gazetelerinin web sayfalarının arama özelliği olmamasından dolayı araştırma kapsamında çıkarılmış ve araştırmaya diğer altı gazete üzerinden devam edilmiştir. Arama özelliği olan web sayfalarında "turizm, turist, turistik çekicilik, rekreasyon, festival, etkinlik, fuar" anahtar sözcükleriyle taramalar yapılarak 2012 yılından 2019 yılına kadar toplamda 535 habere erişilmiştir. Veriler 2019 yılının Ocak ayında toplanmaya başlanıp, Mayıs ayında veri toplama aşaması bitirilmiştir. Söz konusu anahtar sözcükler konuyla ilgili alanyazında yer alan çalışmalardan hareketle belirlenmiștir. Gazetelerde turizmle ilgili haberler taranırken herhangi bir zaman kısıtı konulmamıștır. Araştırmada turizm ile ilgili haberler içerik analizi ile irdelenmiştir. Söz konusu haberler iki ayrı araştırmacı tarafından kodlanmıştır. Bu kodlama neticesinde, haberlerle ilgili yedi ayrı değişken tespit edilmiştir. Ayrıca bu değişkenler alanyazında yapılan diğer çalışmaların değişkenleriyle de benzerlik göstermiştir (Yüksel, Kaya, Koçak ve Aydın, 2016, 21-40; Ayrancı, Özmen, Yaşar ve Yüksel, 2018, 70-78). Araştırmanın güvenirliği ve geçerliği için içerik analizi farklı bir araştırmacı tarafından daha uygulanmış ve ortaya çıkarılan değişkenler araştırmacılar tarafından karşılaştırılmıştır. Sonuç olarak, araștırmada içerik analizi kapsamında oluşturulan sınıflandırma yedi değişken üzerine inşa edilmiştir. Bu değişkenler, "haberlerin yayın sayıları, "yayın türü", "kökeni", "bilgi kaynağı", "haber içeriklerinin niteliğii", "görsel malzemelerin sunumu" ve "Eskișehir'in çekicilikleri"dir.

\section{Bulgular}

Yerel basının web sayfalarının taranması sonucunda bulgular yedi farklı değişken altında değerlendirilmiştir. Bu kapsamda ilk olarak Eskişehir yerel basınında Eskișehir'deki turizm gelişmeleriyle ilgili haberlerin dağılımı Tablo 1'de verilmiştir.

Tablo 1: Turizmle Ilgili Yazıların Yayımlandığı Yayım Organı

\begin{tabular}{|l|c|c|c|}
\hline Yerel Yayıncı & Haber Sayısı & Haber Yılları & Yüzde (\%) \\
\hline Eskişehir Anadolu Gazetesi & 134 & $2012-2019$ & 25,04 \\
\hline Sakarya & 26 & $2017-2019$ & 4,85 \\
\hline 2 Eylül & 208 & $2017-2019$ & 38,87 \\
\hline Eskişehir Milli İrade & 48 & $2017-2019$ & 8,97 \\
\hline Sonhaber & 104 & $2013-2019$ & 19,43 \\
\hline Yenigün & 15 & $2017-2019$ & 2,80 \\
\hline Toplam & 535 & & 100,0 \\
\hline
\end{tabular}


Bu kapsamda turizmle ilgili haberlere daha çok 2 Eylül Gazetesi'nin web sayfasında yer verildiği, en az turizm haberinin yer aldığı yerel gazete web sayfasının ise Yenigün olduğu görülmüştür. Haberlerin yayın yıllarına bakıldığında Eskişehir Anadolu Gazetesi'nin web sayfasında 2012 yılından itibaren turizm içerikli haberlerin yer aldığı belirlenmiştir. Eskişehir Anadolu Gazetesi'ni, Sonhaber Gazetesi 2013 yılından itibaren yayınladığı haberlerle takip etmektedir. Araştırma kapsamında ele alınan diğer dört gazete olan Sakarya, Eskişehir Milli İrade, Yenigün ve 2 Eylül Gazeteleri'nin ise 2017, 2018 yıllarından başlayarak turizmle ilgili haberlere yer verdiği anlaşılmaktadır.

Gazete web sayfalarının incelenmesi neticesinde turizm yazılarının \%11,58'inin (62 adet) köșe yazısı olduğu, \%88,42'sinin (483 adet) ise "haber" niteliğinde yayın olduğu tespit edilmiştir. Tablo 2'ye bakıldığında ise yazıların büyük çoğunluğunun kökeni olarak ya gazetelerin kendi yayını olduğunu ya da yazıların kökenin neresi olduğunun belirtilmediği görülmektedir. Bu durum dışında kalan haberlerin \%20'sinde ise muhabirin adı bulunmaktadır.

Tablo 2: Turizm Haberlerinin Kökeni

\begin{tabular}{|l|c|c|}
\hline Haberlerin Kökeni & Haber Sayısı & Yüzde (\%) \\
\hline Gazetenin Kendisi veya Belirtilmemiş & 282 & 52,71 \\
\hline Muhabirin Adı & 110 & 20,56 \\
\hline Haber Ajanları & 81 & 15,14 \\
\hline Köşe Yazarı & 62 & 11,58 \\
\hline Toplam & 535 & 100,00 \\
\hline
\end{tabular}

Araştırma kapsamında yerel gazetelerin web sayfalarında yer alan turizme yönelik haber sayıları ve turizm yazılarının kökeni incelendikten sonra haberin temelini olușturan haberlerin bilgi kaynaklarının neler olduğuna bakılmıştır. Turizm haberlerinin bilgi kaynakları Tablo 3'ten de anlaşılacağı üzere turizm sektörü üzerinde söz sahibi olan yerel yönetimler, kamu görevlileri ve Sivil Toplum Kuruluşlarıdır (STK). Kamu kurumlarının, Eskişehir turizmi için en önemli bilgi kaynakları olduğu açıkça görülmektedir. Özel sektörün Eskişehir turizmiyle ilgili yapılan haberlere bilgi kaynağı olabilme rolünün oldukça kısıtlı olduğu söylenebilir.

Tablo 3: Eskişehir'in Yerel Gazetelerinin Web Sayfalarında Yer Alan Turizm Haberlerinin Bilgi Kaynakları

\begin{tabular}{|l|c|c|}
\hline Haber Kaynakları & Haber Sayısı & Yüzde (\%) \\
\hline Yerel Yönetimler (Belediyeler) & 103 & 19,20 \\
\hline Kamu Görevlisi/Bürokrat & 97 & 18,13 \\
\hline Sivil Toplum Kuruluşları (Ticaret Odası vb.) & 88 & 16,44 \\
\hline Milletvekili, Politikacı & 60 & 11,21 \\
\hline İş İnsanı (Özel Sektör) & 47 & 8,78 \\
\hline Akademisyen & 38 & 7,10 \\
\hline Turizm ve Kültür Bakanı veya İ Turizm Müdürü & 35 & 6,54 \\
\hline Köşe Yazarının Kendisi & 17 & 3,17 \\
\hline Yerli, Akademik, Bilimsel Çalışmalar & 14 & 2,61 \\
\hline Diğer & 36 & 6,72 \\
\hline Toplam & 535 & 100 \\
\hline
\end{tabular}

Eskişehir turizmi ile ilgili çıkan haberlerin içeriklerinin niteliğine bakıldığında "ümit veren" ve "bilgi veren" niteliklerin ön plan çıktığı görülmektedir. Tablo 4'te ayrıca dikkati çeken bir nokta ise Eskişehir turizmi ile ilgili yapılan haberlerde eleştirel, olumsuz yanlara 
dikkat çeken haberlerin sayıca az oluşudur. Genel anlamda yerel gazetelerin web sayfaları turizm haberleri kapsamında değerlendirildiğinde, haberlerin büyük bir çoğunluğunun olumlu içeriklere sahip olduğu dikkati çekmektedir. Haber içeriklerin geneli, Eskiş̧ehir turizminin gelecekte hep daha iyi olacağına dair bilgiler içermektedir. Ancak geleceğe dönük olarak Eskişehir'in hangi unsurlarla öne çıkacağına dair bilgi veren haber sayısı oldukça azdır. Haberlerin büyük çoğunluğu geçmiş yılların verileri üzerinden bir değerlendirme yaparak, Eskişehir'e gelen ziyaretçi sayılarındaki artışları kapsamaktadır. Ayrıca gerek yerel gerek merkezi bürokratların verdiği mesajlar yer almaktadır. $\mathrm{Bu}$ nedenle bilgi ve ümit veren haber içeriklerinin fazla oluşu anlaşllabilirdir.

Tablo 4: Eskişehir'in Yerel Gazetelerinin Web Sayfalarında Yer Alan Turizm Haberlerinin Niteliği

\begin{tabular}{|l|c|c|}
\hline Haberlerin niteliği & Haber Sayısı & Yüzde (\%) \\
\hline Bilgi veren & 470 & 40,37 \\
\hline Ümit veren & 251 & 21,56 \\
\hline Takdir eden & 173 & 14,86 \\
\hline Hedef içeren & 84 & 7,21 \\
\hline Motive eden & 62 & 5,32 \\
\hline Uyarı yapan & 46 & 3,95 \\
\hline Eleştiri yapan & 14 & 1,20 \\
\hline Yerel ürünleri ön plana çıkartan & 37 & 3,17 \\
\hline Diğer & 27 & 2,31 \\
\hline Toplam & 1164 & 100 \\
\hline
\end{tabular}

$\mathrm{Bu}$ çalışma kapsamında ayrıca, yerel gazetelerin verdiği turizm haberlerinin görsel unsurları da incelemeye dahil edilmiștir. Tablo 5'ten görüleceği üzere görsellerin yaklașık \%90'lık bir kısmını turizm haberlerine konu olan kişi/kișilerin görüntülerini ve Eskișehir'e ait șehir görsellerinin oluşturduğu anlaşılmaktadır. Turizm haberlerinin $\% 7,5^{\prime}$ lik kısmında ise karikatür-mizansen, logo, tablo görseli kullanılırken;haberlerin \%2,5’lik kısmında ise hiçbir görsel kullanılmamıștır.

Tablo 5: Eskişehir'in Yerel Gazetelerinin Web Sayfalarında Görsel Malzemelerin Sunumu

\begin{tabular}{|l|c|c|}
\hline Görsel İçeriği & Haber Sayısı & Yüzde (\%) \\
\hline Kişi/kişilerin Görüntüsü & 259 & 46,83 \\
\hline Eskişehir Şehir Görseli & 247 & 44,66 \\
\hline Karikatür-Mizansen & 13 & 2,35 \\
\hline Logo & 11 & 1,98 \\
\hline Tablo & 9 & 1,62 \\
\hline Görsel Yok & 14 & 2,53 \\
\hline Toplam & 553 & 100 \\
\hline
\end{tabular}

Araştırma kapsamında Eskişehir yerel gazetelerinde, Eskişehir'in yerel çekiciliklerinin sunumu analiz edilmiștir. Tablo 6 incelendiğinde, Eskișehir turizmiyle ilgili yapılan 535 haberin 257 tanesinin (Turizm haberleri içindeki payı \%48) Eskişehir'in çekicilikleriyle ilgili olduğu görülmektedir. Eskişehir'in çekicilikleri içinde yaklaşık \%54'lük paya sahip ve en çok haber yapılan üç çekicilik unsurunun parklar/bahçeler, müzeler ve Tarihi Odunpazarı evleri olduğu görülmektedir. En az haber yapılan çekiciliklerin ise İnanç Merkezleri olduğu sonucuna ulaşılmıştır. 
Tablo 6: Eskişehir'in Yerel Gazetelerinin Web Sayfalarında Yer Alan Turistik Cekicilik Unsurlarının Sunumu

\begin{tabular}{|l|c|c|}
\hline Turistik Çekicilik Unsurları & Haber Sayısı & Yüzde (\%) \\
\hline Parklar/Bahçeler & 57 & 22,17 \\
\hline Müzeler & 48 & 18,67 \\
\hline Tarihi Odunpazarı Evleri & 34 & 13,22 \\
\hline Yerel Ürünler (Lületaşı vb.) & 28 & 10,89 \\
\hline Sağlık/Termal Turizm & 22 & 8,56 \\
\hline Kongre/Fuar Turizmi & 17 & 6,61 \\
\hline Ünlü Cadde ve Sokakları & 16 & 6,22 \\
\hline İnanç Merkezleri & 13 & 5,05 \\
\hline Diğer & 22 & 8,56 \\
\hline Toplam & 257 & 100 \\
\hline
\end{tabular}

\section{Sonuç ve Değerlendirme}

Araştırma kapsamında Eskişehir ilinin yerel gazetelerinin web sayfalarında yer alan turizm haberleri incelenmiştir. Bu kapsamda, turizm haberlerinin sayısı, yayın türü, kökeni, bilgi kaynağı, haber içeriklerinin niteliği, görsel malzemelerin sunumu ve Eskişehir'in sahip olduğu çekiciliklerin haberleştirilmesi konuları ele alınmıştır. İnceleme neticesinde; Eskișehir Anadolu, 2 Eylül ve Sonhaber gazetelerinin Eskişehir turizmi ile ilgili çok sayıda haber yaptığı görülmüştür. Diğer yandan Sakarya, Eskişehir Milli İrade ve Yenigüngazetelerinin Eskişehir turizmi ile ilgili haber sayılarının düşük olduğu belirlenmiştir. Bu durum söz konusu gazetelerin web sayfalarının diğer üç gazeteye göre daha yeni olmasından kaynaklanabilir. Yalnızca 2018 ve 2019 yılı haber sayıları incelendiğinde, altı gazetenin de turizm haber sayılarının birbirine yakın olduğu ifade edilebilir.

Çalışmanın, Ayrancı, Özmen, Yaşar ve Yüksel'in (2018) sağlık turizmi üzerine yaptığı çalışmayla haberlerin kökeni yönünden benzerlik gösterdiği anlaşılmıştır.Ancak her iki çalıșma haberlerin öznesi yönünden karşılaştırıldığında farklılık göstermektedir. Ayrancı, Özmen, Yaşar ve Yüksel'in (2018) çalışmasında, sağlı turizmi içeriklerinin öznesi rolünde genel anlamda özel sektör varken, bu çalışmada Eskişehir turizmi haberlerinin yaklaşık \%60'ını kamu kurumları veya kişileri oluşturmaktadır. Ayrancı ve arkadaşları (2018) çalışmada sağlık turizmi haberlerinin genel olarak bahar aylarında arttığını vurgulamışlardır. Buradan yola çıkılarak bahar aylarıyla bireylerin mevsimsel olarak seyahat etme davranışının arttığı söylenebilir. Bu duruma ek olarak söz konusu çalışmada, özel sektör kaynaklı haberlerin fazla olması, özel sektörün seyahat etme davranışından pay alma isteği ile ilişkilendirilebilir. Ancak, şehir turizmi olarak nitelendirilen Eskişehir turizmiyle ilgili haberlerin genel olarak yıl içine dengeli dağılması, kamu kaynaklı haberlerin fazla olmasıyla açıklanabilir. Çalışmada Eskişehir ile ilgili haber kaynaklarında ağırlıklı olarak kamu kurumlarının olması, Williams'ın $(2006,486)$ çalışmasının sonuçlarıyla örtüşür niteliktedir. Williams'ın çalışmasındageleneksel medyada yer alan eski reklam alışkanlıkların değişmesi vurgulanmıştır. Buradan hareketle; özel sektörün alternatif medya platformlarına özellikle sosyal medyaya yönelme eğilimindedir. Bu durumun sonucunda özel sektörün geleneksel medyada daha az haber kaynağı rolüne dönüştüğü düşünülebilir.

Lindstörm (2010) destinasyon imajının doğru ve kolay bir biçimde oluşturulabilmesini, medya ve turizm arasındaki kurulan ilişkinin boyutuyla açıklamaktadır. Bu çalışmanın önemi tam bu noktada ortaya çıkmaktadır. Eskişehir'in turistik çekiciliklerinin medya da 
ne denli yer aldığının ortaya çıkarılması, Eskişehir'in destinasyon imajı oluşturulurken hangi unsurları öne çıkarıldığının anlaşılmasını kolaylaştıracaktır. Bu çalışmaya benzer bir çalışma 2016 yılında Ormankıran, Başçı ve Aknar tarafından yapılmıştır. Araştırmacılar çalışmada Çorum turizminin ulusal medyada hangi unsurlarla yer aldığını belirlemeye çalışmışlardır. Çalışma sonucunda Çorum turizmi ile ilgili haberlerin yaklaşık \%90'ının olay-durum, yaklaşık \%10'unun ise köşe yazısı olduğu belirlenmiştir. Söz konusu çalışmada yer alan bu oranlar, çalıșmanın sonuçları ile benzerlik göstermektedir. Diğer yandan Ormankıran, Başçı ve Aknar (2016) çalışmada, Çorum turizmi ile ilgili haberlerin yaklaşık \%53'ünde görsellerin kullanıldığını belirtmişlerdir. Araştırmacılar tarafından belirtilen bu oran, Eskişehir turizmi ile ilgili haberlerde kullanılan görsellerin çok altındadır. Zira çalışma kapsamında Eskişehir turizmi ile ilgili haberlerde görsel kullanım oranı yaklaşık \%90 olarak belirlenmiştir. Bu durum ulusal medyadaki haber sayısının yerel medyadaki haber sayısına oranla daha fazla olmasından kaynaklanabilir. Daha fazla haberin daha fazla haber alanı kaplamasından dolayı, ulusal medya da görsel kullanımının daha az kullanıldığı düşünülebilir. Kısaca yerel medyanın kendi şehriyle ilgili haberlere daha geniş yer ayırması neticesinde görsel kullanımının artması sonucunu doğurmaktadır.

Eskişehir turizmi ile ilgili yazılan metinler incelendiğinde, metinlerin büyük çoğunluğunun haber olduğu görülmektedir. Turizm haberleri içinde Eskişehir turizmiyle ilgili doğrudan yazılan köşe yazıları oldukça azdır. Ayrıca turizm haberlerinin kökeni genel olarak, gazetenin kendi ismiyle yayınlanan metinlerden oluşmaktadır. Haber kökeninin belli olduğu (muhabirin/köşe yazarının adı veya haber ajansının adı) turizm haberleri ise araștırma kapsamında ele alınan haberlerin diğer yarısını olușturmaktadır. Haberlerin kökenini, haber kaynaklarıyla birlikte değerlendirmek daha doğru olacaktır. Yerel gazetelerin isimsiz olarak yayınladığı turizm haberlerin önemli bir kısmının yerel yönetim temsilcilerinin veya kamu görevlilerin yaptığı açıklamalar olduğu dikkat çekmiştir. Bu durum Eskişehir turizminde ağırlıklı olarak söz sahibi tarafın kamu kurum ve kuruluşları olduğunu da göstermektedir. Haber kaynakları arasında özel sektör payının \%10 düzeylerinde olması, Eskişehir turizminin kamuya bağlı olarak geliştiğinin önemli bir yansımasıdır.

Turizm haberleri içerikleri bakımından değerlendirildiğinde, turizm haberlerinin önemli bir kısmının bilgi verme, ümit verme, motive etme gibi olumlu içeriklere sahip olduğu dikkati çekmiştir. Turizmle ilgili olarak olumlu haberlerin çok olmasının bir diğer nedeninin, haber kaynaklarının genellikle kamu kurum ve kuruluşları veya bu kurumlarda çalışan bürokratların olmasından kaynaklandığındandır. Çünkü olası eleştiri ve önerilerin özel sektörde olması beklenmektedir ancak Eskişehir turizmi özelinde özel sektör haberlerinin az olması belki de eleştirel haber içeriklerinin \%1,5 düzeylerinde kalmasına neden olmuştur. Benzer şekilde kamu haber kaynaklarının fazla olması haber içeriklerinde kullanılan görsellerin içeriklerini de önemli ölçüde etkilemiştir. Araștırma kapsamında ele alınan Eskişehir'e dönük turizm haberlerinin yarıya yakının da kişi veya kişilerin görüntüsü kullanılmıştır. Bu durum Eskişehir'in çekiciliklerinin medyada görsel olarak yer bulması konusunda bir eksiklik olarak göze çarpmaktadır. Eskişehir turizmine yönelik haberlerin ancak \%45'ine yakın bir kısmında Eskișehir'in sahip olduğu çekicilik unsurlarına yer verilmiştir. Halbuki günümüz dünyasında internetin önemli bir yere sahip olduğu düşünüldügü̈nde yerel gazetelerin web sayfalarında yayınlanan haber içeriklerinin merak uyandırıcı ve harekete geçirici bir etkisinin olması beklenmektedir. 
Eskişehir'e yönelik olarak yapılacak turizm haberlerinde şehrin çekiciliklerini yansıtan görsellerin veya motiflerin kullanılmasının șehre olan talebi artıracağı düşünülmektedir.

Yerel gazetelerin web sayfalarında Eskişehir'in çekicilik unsurları olarak parklar, müzeler, tarihi bölgeler, farklı turizm türleri, ünlenen cadde ve sokaklarının kullanıldığı görülmektedir. Eskişehir iline bu kapsamda bakıldığında kentsel destinasyon çekicilikleri olarak oldukça çeşitli çekicilik unsularını barındırdığı görülmektedir. Ancak bu noktada yapılan haberlerin çekicilik unsurlarını içerdiği ancak bu çekicilik unsurlarının okuyucuyu harekete geçirecek biçimde sunulmadığı görülmüştür. Çalaışma haberlerin niteliği açısından ele alındığında görülmektedir ki haberlerin büyük çoğunluğunun bilgi verme amacı taşımaktadır. Halbuki yerel gazeteler, bütüncül bir bakış açısıyla yerel bir pazarlama aracı gibi de kullanabilir. Bu önerinin temel nedeni ise bireylerin gitmek istedikleri bir destinasyon hakkında internet üzerinde arama yaptıklarında yerel gazetelerin çeşitli haberlerini görmelerindendir. Haber içeriklerinin harekete geçirici bir etki gösterdiğinde kişilerin seyahat etme motivasyonlarının artacağı düşünülebilir.

Araştırma kapsamında yerel gazetelerin basılı yayınlarının incelenmemesi araştırmanın bir kısıtı olarak ifade edilebilir. Bu kısıt neticesinde Sakarya, Eskișehir Milli İrade ve Yenigün gazetelerinin 2018 yılı öncesi haberlerine ulaşılamamıştır. Ancak yine de toplamda 535 olan turizmle ilgili haber sayısı, Eskişehir turizminin yerel gazetelerin web sayfalarından incelenmesi için araştırmacılar tarafından yeterli görülmüştür. Daha sonra yapılacak çalışmalarda ulusal basında Eskișehir turizmi ile ilgili çıkan haberler incelenebilir. Böylece yapılacak çalışmanın sonuçlarıyla; bu çalışma kapsamında ele alınan yerel gazetelerden elde edilen sonuçlar kıyaslanabilir. Bu çalışmaların ortak sonucunda da yazılı medyada Eskişehir turizmine yönelik bütüncül bakış açının nasıl olduğu ortaya konulabilir.

\section{Kaynakça}

Ayrancı, P., Ayaz, F., Yaşar, N. ve Yüksel, E. (2018). Sağlık turizmi içeriklerinin gazetelerdeki sunumu. Elektronik Cumhuriyet İletişimDergisi, 1(1), 64-80.

Bargeman, B. ve van der Poel, H. (2006). The role of routines in the vacation decisionmaking process of Dutch vacationers. Tourism Management, 27(4), 707-720.

Buhalis, D. (2000). Marketing the competitive destination of the future. Tourism management, 21(1), 97-116.

Cılızoğlu, G. (2011). Kitle iletişim araçlarında yer alan kurgusal sosyal mesajlar: televizyon dizilerinde kitleselleştirilen değerlere yönelik bir analiz. Selçuk Üniversitesi İletişim Fakültesi Akademik Dergisi, 6(4), 90-100.

Crouch, D., Jackson, R. ve Thompson, F.(Eds.). (2005). The media and the tourist imagination: Converging cultures. NY: Routledge.

Goeldner, C. R. ve Ritchie, J. R. B. (2009). Tourism principles, practices, philosophies (11. Baskı). USA: John Wiley ve Sons, Inc.

Gunn, C.A. (1994). Tourism planning. Washington: Taylor ve Francis.

Hall, C. M. (2000). Tourism planning: policies, processes, relationships. U.K.: Prentice Hall.

Hsu, T-K., Tsai Y-F. ve Wu, H-H. (2009). The preference analysis for tourist choice of destination: a case study of taiwan. Tourism Management, 30: 288-297. 
Holloway, J. C., Humphreys, C. ve Davidson, R. (2009). The business of tourism (8. Baskı). England: Pearson Education Limited.

Karabıyık, N. ve Sümerİnci, B. (2012). Destinasyon pazarlamasinda pazarlama stratejisi ve konumlandırma çalışmalarına kavramsal yaklaşım. İstanbul Sosyal Bilimler Dergisi, 1,1-19.

Kim, K., Noh, J. ve Jogaratnam G. (2006). Multi-destination segmentation based on push and pull motives: pleasure trips of students at a u.s. university. Journal of Travel ve Tourism Marketing, 21(2/3): 1-15.

Klenosky, D. B. (2002). The "pull" of tourism destinations: A means-end investigation.Journal of travel research, 40(4), 396-403.

Kozak, N. (2010). Turizm Pazarlaması (3. Baskı). Ankara: Detay Yayıncılık.

Lindström K. (2010). The creation and mediationof news media's images of touristdestinations: conceptions and intentionsamong swedish travel journalists and their main sources, International Tourism and Media Conference. 25th$28^{\text {th }}$ November. La Trobe University and Monash University: Melbourne.

Medlik, S. (1993). Dictionary of travel, tourism and hospitality. Oxford: Butterworth Heinemann.

Metelka, C.J. (1990). The dictionary of hospitality, travel and tourism. Albany: Delmar Publishers.

Milburn, M. A. (1998). Sosyal psikolojik açıdan kamuoyu ve siyaset, Çev: A. Dönmez ve V. Duyan. Ankara: İmge Kitabevi

Mohammad, B. ve Mat Som, A.P. (2010). An analysis of push and pull travel motivations of foreign tourists to jordan. International Journal of Business and Management, 5, $41-50$.

Pride, R., Morgan, N. ve Pritchard, A. (2004). Destination branding. Creating the unique destination proposition. Oxford: Elsevier Butterworth-Heinemann.

Oh, H. C., Uysal, M. ve Weaver, P. A. (1995). Product bundles and market segments based on travel motivations: A canonical correlation approach. International Journal of Hospitality Management, 14(2), 123-137.

Ormankıran, Y., Başçı, A. ve Aknar, A. (2016). Ulusal gazetelerin internet sitelerinde çorum turizmi içerik analizine dayalı bir değerlendirme (ss 203-211). Uluslararası Bütün Yönleriyle Çorum Sempozyumu: Çorum.

Prayag, G. ve Ryan, C. (2011). The relationship between the 'push' and 'pull' factors of a tourist destination: the role of nationality - an analytical qualitative research approach. Current Issues in Tourism, 14 (2): 121-143.

Singer, J.L. ve Singer, D.G. (1998). Barney ve Friends as entertainment and education: Evaluating the quality and effectiveness of a television series for preschool children, Editör: J. K. Asamenve G. L. Berry, İçinde. Research paradigms, television, and social behavior (pp. 305-367). Thousand Oaks, CA: Sage.

Türk Dil Kurumu (2019). Destinasyon kelimesi karşılığı. tdk.gov.tr/index.php?option=com_ btsvearama=kelimeveguid=TDK.GTS.5d888f42d5df17.04821072. Erişim Tarihi: 23.09.2019. 
Timisi, N. (2003). Yeni iletişim teknolojileri ve demokrasi. Ankara: Dost Kitabevi.

Tosun, C. ve Jenkins, C. L. (1996). Regional planning approaches to tourism development: the case of turkey. Tourism Management, 17 (7): 519-531.

Türkeri, İ. (2014). Destinasyon aidiyeti oluşturulmasında destinasyon imajının ve kişiliğinin rolü: kış turizmi örneği (Palandöken Kayak Merkezi). (Yayımlanmamış Yüksek Lisans Tezi). Atatürk Üniversitesi/Sosyal Bilimler Enstitüsü, Turizm İşletmeciliği ve Otelcilik Ana BilimDalı, Erzurum.

Usta, Ö. (2008). Turizm, genel ve yapısal yaklaşım. Ankara: DetayYayıncılık.

Williams, A. (2006). Tourism and hospitality marketing: fantasy, feeling and fun. International Journal of Contemporary Hospitality Management, 18(6), 482-495

Yoon, Y. ve Uysal, M. (2005). An examination of effects of motivation and satisfaction on destination loyalty: A structural model. Tourism Management, 26, 45 - 56.

Yüksel, E., Kaya, Y. A., Koçak, A. ve Aydın, S. (2016). Türkiye de sağlık konulu yayınların analizi. e-Kurgu Anadolu Üniversitesi İletișim Bilimleri Fakültesi Dergisi. 24(1): 17 43. 


\title{
Presentation of Eskişehir's Destination Attractions in Local Media
}

\author{
Çağdaş Aydın (Res. Asst.) \\ Ceren Aydın
}

\section{Extended Abstract}

Mass media has entered the lives of communities around the beginning of the $20^{\text {th }}$ century and has since become an element affecting the behavior of societies. With mass media, all kinds of ideas, tangible or abstract commodities had the opportunity to reach larger masses of people than ever before. In this sense, mass media is perceived as an essential means in the development of a society and the individuals it comprises. Some activities are required in order to commercialize the natural, historical, artificial, and cultural attractions of destinations. The primary activity is to try and make place for the advertisements, news regarding the destination or social responsibility projects taking place in the area. Nowadays, before visiting a destination, people will look for different sources of information, consulting the opinions of previous visitors, or local sources, and try to acquire the most tangible data. As such, Eskişehir's elements of destination attractions can be found in the local newspapers. Within the scope of this study, it was aimed to determine the qualitative and quantitative properties of the attractions found in the local newspapers. In this context, the question of how the attractions of Eskişehir destination were addressed in the local and regional newspapers was studied using content analysis method. Determination of how Eskişehir's attractions were presented in local newspapers constitutes the study's contribution to literature. On the other hand, to what extent do the attractions of Eskişehir appear in the local media and what elements are highlighted for the readers were inspected. In this framework, it was studied whether local media discuss the attractions to a sufficient degree.

\section{Method}

In this research, the manner in which Eskişehir's tourism destination attraction elements were treated in local media was studied. In other words, the main research question is "how are Eskișehir's tourist attractions are presented in the local media?" The other research questions addressed are as follows:

1. What are the types, roots, information and news sources of the texts appearing in Eskișehir's local media regarding the tourism of the city?

2. What is the usage rate of images? What are the contents of these images?

3. What are the themes and subtopics of the articles about tourism in Eskişehir?

4. What is the place of tourism related news in relation to other news stories in local newspapers?

In this context, the method of document scanning which is one of the qualitative methods was employed in this study. At the first stage, the researchers specified the local newspapers of Eskişehir. The newspapers in question are İstikbal, Eskişehir Anadolu, Sakarya, 2 Eylül, Milli İrade, Sonhaber, Şehir and Yenigün newspapers. Among these, Şehir and İstikbal were left out of the scope of the research due to the lack of a search function in their websites and the remaining six newspapers were investigated. On the webpages with search bars, the keywords "tourism, tourist, tourist attractions, recreation, 
festival, event, fair" were searched and a total of 535 news stories were collected. The data collection began in January 2019 and ended in May. The keywords mentioned were selected from previous studies in the literature. No time constraints were put during the data scanning. In the research, tourism related dews pieces were examined with content analysis. The news stories were coded by two researchers. As a result of this codification, seven distinct variables were determined. To ensure the reliability and validity of the research, content analysis was made by another researcher as well, and the variables were met by the researchers. As a result, the classification determined by the content analysis was structured upon the seven variables. These variables are "publication numbers," "publication type," "source," "source of information," "the quality of news content," "presentation of images," and "attractions of Eskişehir."

\section{Conclusion and Evaluation}

Within the scope of this study, tourism related news found in Eskișehir's local media webpages. In this context, the number, publication type, source, source of information, quality of news content, presentation of images, and the communication of Eskișehir's attractions have been investigated. As the result of the investigation, it was found that Eskişehir Anadolu, 2 Eylül and Sonhaber newspapers published the largest quantity of articles regarding tourism in Eskişehir. Sakarya, Eskişehir Milli İrade and Yenigün newspapers, on the other hand, have been found to have a lower rate of tourism related news. This may be due to the fact that these newspapers are newer in relation to the other outlets. When the number of news articles in 2018 and 2019 alone are investigated, the numbers of tourism related news pieces were observed to be close. When the contents of the news articles were inspected, it was found remarkable how the majority of the articles had positive content such as imparting information, encouraging hope, and motivation. One reason for the bulk of positive content in tourism related news is that the sources of most of these articles are state institutions and organizations or bureaucrats working for these institutions. In that, it is expected that criticisms and suggestions are to be found in private sector; however, since private sector related news with regard to Eskişehir's tourism, the percentage of critical articles remained around 1,5. It was discovered that parks, museums, historical sites, various tourism types, famous streets and districts were presented as the tourism attractions of Eskișehir in the webpages of local news outlets. When the city of Eskișehir is viewed from this perspective, it is seen that urban destination attractions involve varied attraction elements. However, at this point, it was determined that even though the news articles involved the attractions, they were not presented in a way that might motivate the reader to act. When the news articles were inspected from a qualitative perspective, most of them aimed to inform. Whereas local newspapers can be used as local tools of marketing from a holistic viewpoint. The primary basis of this suggestion is that when individuals search the web about a destination, they see various news articles from local newspapers. It can be argued that when news articles have a motivative effect, the individuals may be convinced to act.

In the scope of this research, it can be said that the lack of information from printed press is a shortcoming of this study. As a result of this shortcoming, news stories of Sakarya, Eskișehir Milli İrade and Yenigün newspapers from before the year 2018 could not be obtained. However, the total number of 535 news articles that have been obtained were found to be sufficient by the researchers as a means to investigate the tourism of Eskişehir in the webpages of local newspapers. Future research may involve the investigation of 
news articles regarding Eskişehir's tourism as they appear on national media outlets. Thus, the result of such a study can be compared and contrasted with the results of the inspection of local media. As a collaborative result of these studies, a holistic view on how printed media perceives the tourism of Eskişehir.

Keywords: Destination Attractions, Tourism News, Local Press, Eskişehir. 